\title{
THE USE OF PARTIAL LEAST SQUARES MODELING IN FINANCE BUSINESS PARTNERING RESEARCH
}

\author{
${ }^{\mathrm{a} A m i n}$ Tohari ${ }^{1}{ }^{\mathrm{b}}$ Faisol, ${ }^{\mathrm{c}}$ Aeri Rachmad \\ ${ }^{a, b}$ Faculty of Economic and Business, University of Nusantara PGRI Kediri, Mojoroto, Kediri \\ ${ }^{\mathrm{c} D}$ Departement of Enginering, University of Trunojoyo Madura 1 Telang, Kamal, Bangkalan \\ E-mail: amin.tohari@unpkediri.ac.id,faisol_hambali@yahoo.co.id, aery_r@yahoo.com
}

\begin{abstract}
Structural equation modeling (SEM) is a set of statistical techniques that allows testing a model that is built between one or more endogenous variables with one or more exogenous variables, where each endogenous and exogenous variable can be in the form of latent or a construct built from several variables of manifest or indicator. There is Structural Equation Modeling (SEM) based on covariance and variance, known as Partial Least Square (PLS), SEM-PLS is a powerful and flexible analysis method. This research provides about the application of SEM-PLS in the field of managerial accounting system, namely the application of non-financial performance's role that delivers the sustainability of the company's financial performance. Based on the results obtained, it can be concluded that partial least squares can be applied to model finance business partnering, and it is known that employee performance and internal process performance affect significantly in mediating between finance business partnering and firms' financial performance. This study provides, the first, empirical evidence that nonfinancial performance, such as employee competency, the internal process can be increased by regarding finance business partnering (FPB). It also presents practical implications recommending that manufacturing firms should motivate the employees in finance staff to be involved in various decision making processes.
\end{abstract}

Key words: Finance Business Partnering, Non-Financial Aspect, PLS, SEM.

\footnotetext{
${ }^{1}$ Corresponding author
} 


\section{INTRODUCTION}

Structural equation modeling (SEM) is a set of statistical techniques that allows testing a model that is built between one or more endogenous variables with one or more exogenous variables, where each endogenous and exogenous variable can be in the form of latent or a construct built from several variables of manifest or indicator. The Structural Equation Model (SEM) examines the structure of the reciprocal relationship expressed in a series of equations, similar to a series of multiple regression equations. This equation describes all of the relationships between the constructs (dependent and independent variables) involved in the analysis. Constructs are unobservable or latent factors represented by several variables such as variables that represent factors in factor analysis [1].

In general, there is Structural Equation Modeling (SEM) based on covariance and variance, known as Partial Least Square (PLS). SEM-PLS is a powerful and flexible analysis method because of its nature that can be used for various data measurement scales (nominal, ordinal, interval, and ratio), can be used for small sample sizes, and does not require a normal multivariate distribution [2].

SEM-PLS has been discussed widely and used in various fields, illustrate the econometric applications and interpretations of various PLS algoritms using $\mathrm{R}$ programming [3]; present a new approach to consumer behavior analysis by generating a tailor-made consumer behavior model [4]; introduce the essential components and variants of structural equation modeling (SEM), synthesize the common issues in SEM applications, and share our views on SEM's future in ecological research [5]; discussions, and developments have led to substantial changes in the understanding and use of PLS [6]; modeling health status by using structural equation modeling in Kediri Regency [7]; test islamic bank financing to small medium enterprises performance [8]; The Role of Perceived Control, Enjoyment, Cost, Sustainability and Trust on Intention to Use Smart Meters: An Empirical Study Using SEM-PLS [9]; model the effect of awareness on the success of IT Governance implementation: A partial least squares structural equation modeling approach [10]; test the mediating effect of overall fairness between specific justice type and employees' citizenship behaviour and psychological ownership [11]; identify paths and predictive power of students' satisfaction during team-based learning (TBL) activities in the faculty of life sciences using partial least squares structural equation modelling [12]; explains how to perform and report empirical analyses using PLS-PM including the latest enhancements, and illustrates its application with a fictive example on business value of social media [13].

In July 2018, the Indonesian Ministry of Industry declared a blueprint for "implementing the Making Indonesia 4.0 initiative and becoming a Global Top 10 Economy by 2030 , which also marks the start of the transition from the conventional manufacturing industry to a more advanced industrial economy, called industry 4.0. Today, manufacturing companies in Indonesia operate in a rapidly changing and competitive environment, and they need to obtain accurate information for business decision making and to improve their performance in a sustainable manner, and maintain a competitive advantage. Under these circumstances, the Ministry of Industry and the Ministry of Finance must shift their role from recording data to assisting in the decision-making process [14]. Companies should also consider finance to be business partners [15], an approach known as "financial business partnering" (FBP). In 2015, The Chartered Global Management Accountant emphasized that FBP can play an active role in improving decision quality and ensuring long-term business success. Many experts also consider FBP as one of the influential factors that affect the foundation of successful business performance improvement.

Apart from the discussion regarding the important role of FBP on the company's financial performance, to date, existing research has examined the influence of several factors on the company's financial performance, such as corporate governance [16]; [17]; [18] and corporate social responsibility [19]; [20]. However, no research examines in depth the relationship between FBP and company financial performance empirically. Moreover, the role of nonfinancial measures has not been explored in this context. Previous studies have investigated the influence of controllers on 
firm performance, and conflicting results have been presented. Several studies have shown that controller participation in FBP results in increased firm performance [15]. However, other studies have found that FBP causes a decrease in firm performance due to the influence of "organizational laxness" [21]. These contradictory results have not succeeded in answering the key question: Can the implementation of FBP lead to an increase in company performance? And what is the influence of non-financial factors in this? Understanding the relationship between firm performance and FBP, as well as the role of non-financial information in this context, is critical to management strategy and business development.

Therefore, the objectives of this research are to examine by applying SEM-PLS in terms of 1) if there is a significant relationship between finance business partnering and firm's financial performance in terms of profit, reduction in cost and sales volume. 2) If the relationship between the level of finance business partnering and the target firm's financial performance in terms of product, satisfaction and service is mediated by employee's performance. 3) if the relationship between the level of finance business partnering and the target firm's financial performance is mediated by internal process performance. 4) if the relationship between the level of finance business partnering and the target firm's financial performance is mediated by internal process performance is mediated by market performance. 5) if there is a significant relationship between internal process performance and firm's financial performance. 6) if there is a significant relationship between internal process performance and firm's financial performance. 7) if there is a significant relationship between market performance and firm's financial performance.

This research provides about the application of SEM-PLS in the field of managerial accounting system, namely the application of non-financial performance's role that delivers the sustainability of the company's financial performance. This research gives four contributions. First, awake the motivation concerning elements of finance business partnering and the advantages of finance business partnering among manufacturing firms in Indonesia. Second, it is the newest study that attempts to determine the elements of non-financial performance as a mediator to develop firms' performance. Third, this study broadens to the theory of the existing literature in this era by conveying that the relationship between finance business partnering and firm performance can be developed by reflecting the mediating impact of non-financial factors. Fourth. It presents useful implications of SEM-PLS regarding the effect of finance business partnering toward firms' financial performance.

This research is structured as follows; material and methods included variance base structural equation model, specification model, and model of PLS, then result and discussion, the last is a conclusion.

\section{MATERIAL AND METHODS}

\section{Variance Based Structural Equation Modeling \\ Analysis in SEM-PLS includes} measurement models or outer models, structural models or inner models and weight relations where the value of latent variables can be estimated. The method of estimating or estimating parameters in PLS uses the least square method, so that the problem of model identification is not a problem for recursive models (has one direction of causality) and avoids problems for models that are nonrecursive or reciprocal between variables [22]. The calculation process is done by iteration, where the iteration will stop when convergent conditions have been reached. The parameter estimation in SEM-PLS was obtained through the following three stages of the iteration process [23]:

1. The first stage is to determine the weight estimate that is used to determine the latent variable score.

2. The second stage is to determine the path estimate that connects the latent variables and the estimated loading between the latent variables and the indicators.

3. The third stage is to determine the estimated mean and location of parameters (regression constant values, intercept) for indicators and latent variables.

\section{Specification Model in SEM-PLS}

Illustration of structural modeling and PLS notation can be seen in the figure below [24]: 


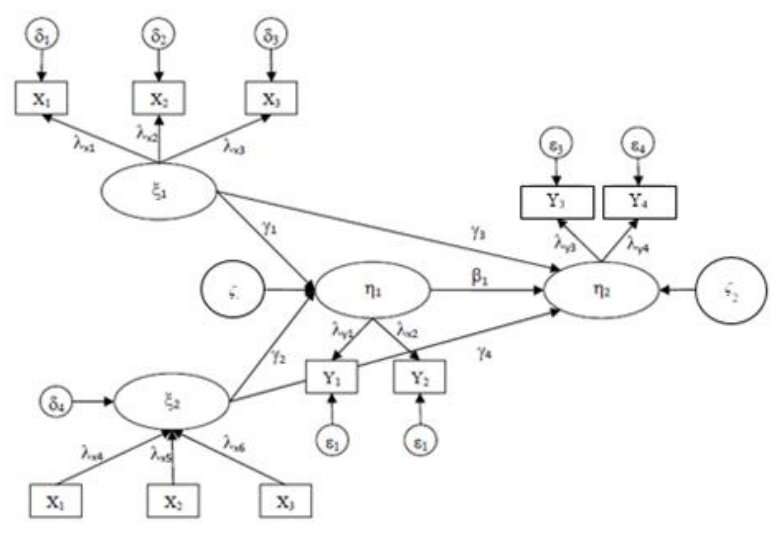

Fig 1. The relationship between variables and indicators in the PLS model

Where the notations used are:

$\xi=\mathrm{Ksi}$, exogenous latent variable

$\eta=$ Eta, endogenous latent variables

$\lambda_{X}=$ Lamda, loading factor exogenous latent variables

$\lambda_{Y}=$ Lamda, loading factor endogenous latent variables

$\beta=$ Beta, the coefficient for the influence of endogenous variables on endogenous variables

$\gamma=$ Gamma, the coefficient for the influence of exogenous variables on endogenous variables

$\zeta=$ Zeta, structural model errors

$\delta=$ Delta, exogenous variable measurement model error

$\varepsilon=$ Epsilon, endogenous variable measurement model error

\section{PLS Model}

Path analysis in PLS-SEM consists of three sets of relationships as follows [22]:

1. The structural model (Inner Model)

The structural model or inner model is a model that shows the relationship or strength of estimation between latent variables or constructs based on substantive theory. The equation model is as follows [24]:

$$
\boldsymbol{\eta}=\mathbf{B} \boldsymbol{\eta}+\boldsymbol{\Gamma} \boldsymbol{\xi}+\boldsymbol{\zeta}
$$

where:

$\boldsymbol{\eta}=$ endogenous latent vector

$\xi=$ exogenous latent vector

$\zeta=$ residual vector (unexplained variance)

$\mathbf{B}=$ coefficient matrix of the influence of endogenous latent on endogenous latent
$\boldsymbol{\Gamma}=$ coefficient matric of the influence exogenous latent to endogenous latent

PLS is designed for a recursive model (a model that has one-way causality), so that the relationship between endogenous latent variables is often referred to as a causal chain system which can be specified as follows [24]:

$$
\eta_{j}=\sum_{i} \beta_{j i} \eta_{i}+\sum_{b} \gamma_{j b} \xi_{b}+\zeta_{j}
$$

where:

$j=$ the number of endogenous variables in the structural equation

$i=$ index from 1 to the number of endogenous variables that become exogenous variables in the structural equation

$b=$ index from 1 to the number of exogenous variables

2. Measurement Model (Outer Model)

A measurement model or outer model is a model that shows how each indicator block relates to its latent variable. Equation models for outer model reflective are as follows [24]:

$$
\begin{aligned}
& \mathbf{x}=\boldsymbol{\Lambda}_{x} \boldsymbol{\xi}+\boldsymbol{\delta}_{x} \\
& \mathbf{y}=\boldsymbol{\Lambda}_{y} \boldsymbol{\eta}+\boldsymbol{\varepsilon}_{y}
\end{aligned}
$$

where $\mathbf{x}$ and $\mathbf{y}$ are vectors of manifest variables or indicators for exogenous latent constructs $(\boldsymbol{\xi})$ and endogenous ( $\boldsymbol{\eta}$ ), $\boldsymbol{\Lambda}_{x}$ and $\boldsymbol{\Lambda}_{y}$ are matrixes of loading which describe the coefficient that relate the latent variable to the indicator, as well $\boldsymbol{\varepsilon}_{x}$ and $\boldsymbol{\varepsilon}_{y}$ which are the residual of measurement error (measurement error).

Equation models for outer model formative as follows [24]:

$$
\begin{gathered}
\boldsymbol{\xi}=\boldsymbol{\Pi}_{\xi} \mathbf{x}+\boldsymbol{\delta}_{\xi} \\
\boldsymbol{\eta}=\boldsymbol{\Pi}_{\eta} \mathbf{y}+\boldsymbol{\varepsilon}_{\eta}
\end{gathered}
$$

where $\xi$ and $\boldsymbol{\eta}$ are exogenous and endogenous latent construct vectors, $\mathbf{x}$ and $\mathbf{y}$ are vectors for manifest variable or indicators for latent exogenous construct ( $\boldsymbol{\xi})$ and endogenous $(\boldsymbol{\eta}) . \boldsymbol{\Pi}_{\xi}$ and $\boldsymbol{\Pi}_{\eta}$ are 
matrix loading which is the coefficient of the relationship for the latent variable and the indicator block, as well $\boldsymbol{\delta}_{\xi}$ and $\boldsymbol{\varepsilon}_{\eta}$ which are the residual of measurement error.

3. Weight Relations

The outer model and inner model provide the specifications that are followed in the estimation of the PLS algorithm. So we need a definition of weight relation to complete it, namely as a weight that connects the outer model and the inner model to form an estimation of the exogenous and endogenous latent variables. The estimation of cases value for each latent variable estimated in PLS [24]:

$$
\begin{aligned}
& \widehat{\xi}_{b}=\sum_{k b} w_{k b} x_{k b} \\
& \hat{\eta}_{i}=\sum_{k i} w_{k i} y_{k i}
\end{aligned}
$$

where $w_{k b}$ and $w_{k i}$ are $k$ weight that is used to estimate latent variable $\xi_{b}$ and $\eta_{i}$. Estimation of the latent variable is a linear aggregate from indicators whose weight values are obtained through the PLS estimation procedure.

Research data collected through online questionnaires. The questionnaires have been distributed through a website called "Ipanelonline or IpanelIndonesia. The target questionnaires are directors, chief of finance, managers of finance, and supervisors in accounting. The questionnaires were also distributed to the students who are attending training classes such as magister student in accounting, "Brawijaya University". All students were suitable for this research.

The respondents were asked to answer on a scale of 5 points ranging from " $1=$ Not at all" to " $5=$ Mostly great" regarding the achievement of goals related to the company's financial performance and the company's nonfinancial performance, including the achievement of goals related to employee performance, internal process performance, and market performance. A higher value indicates a higher level of planned performance achievement. The variables used in this research are: $\mathrm{EP}=$ Employees' Performance; $\mathrm{FPB}=$ Financial Business Partnering; FFP $=$ Firms' Financial Performance; $\mathrm{IPP}=$ Internal Process performance; and MP = Market Performance
PLS-SEM was used in this research because it is also adopted in many research areas, such as management in operating, management in accounting, and accounting [25].

\section{RESULT AND DISCUSSION}

The evaluation of the measurement model (outer model) through loading factor is done to determine the validity of indicators in forming a latent variable, by looking at the convergent validity value of the indicators in the model. Each indicator in the model must fulfill the convergent validity, which has an absolute loading factor of $>0.5$, if there are indicators that do not fulfill the criteria for convergent validity, then the indicators are excluded from the model. The following is the result of convergent validity:

Table 1. Result of Convergent Validity in round 1

\begin{tabular}{llllll}
\hline & EP & FBP & FFP & IPP & MP \\
\hline EP01 & 0.752 & & & & \\
EP02 & 0.463 & & & & \\
EP03 & 0.823 & & & & \\
EP04 & 0.744 & & & & \\
FBP01 & & 0.869 & & & \\
FBP02 & & 0.833 & & & \\
FBP03 & & 0.805 & & & \\
FBP04 & & 0.539 & & & \\
FFP01 & & & 0.669 & & \\
FFP02 & & & 0.896 & & \\
FFP03 & & & 0.824 & & \\
FFP04 & & & 0.396 & & \\
IPP01 & & & & 0.792 & \\
IPP02 & & & & 0.832 & \\
IPP03 & & & & 0.840 & \\
IPP04 & & & & 0.606 & \\
MP01 & & & & & 0.890 \\
MP02 & & & & & 0.852 \\
MP03 & & & & & 0.856 \\
MP04 & & & & & \\
\hline SOU1 & PLS OUtp & &
\end{tabular}

Source: PLS Output

Based on the results obtained from data processing, the EP02 indicator on the employees 'performance variable, the FBP04 indicator on the finance business partnering variable, the FFP01 and FFP04 indicators on the firms' financial performance variable, the IPP04 indicator on the internal process performance variable has an outer loading that is smaller than 0.700 , so that these indicators need to be eliminated from the model, then an evaluation of the remaining indicators is carried out. The following is the 
result of convergent validity in round 2 .

Table 2. Result of Convergent Validity in Round 2

\begin{tabular}{llllll}
\hline & EP & FBP & FFP & IPP & MP \\
\hline EP01 & 0.774 & & & & \\
EP03 & 0.836 & & & & \\
EP04 & 0.770 & & & & \\
FBP01 & & 0.899 & & & \\
FBP02 & & 0.824 & & & \\
FBP03 & 0.777 & & & \\
FFP02 & & & 0.918 & & \\
FFP03 & & 0.870 & & \\
IPP01 & & & & 0.803 & \\
IPP02 & & & & 0.851 & \\
IPP03 & & & & 0.818 & \\
MP01 & & & & & 0.878 \\
MP02 & & & & & 0.851 \\
MP03 & & & & & 0.867 \\
MP04 & & & & 0.831 \\
\hline SSOUrCe: PLS Output & & &
\end{tabular}

Ssource: PLS Output

Based on table 2 above, all indicators have an outer loading that is greater than 0.700 , so there are no indicators to be eliminated from the model. Evaluation of the measurement model (outer model) can also be seen based on average variance extracted (AVE) and composite reliability. Here are the results of average variance extracted (AVE) and composite reliability:

Table 3. Result of Average Variance Extracted

$\begin{array}{ll}\text { Composite } & \begin{array}{l}\text { Average } \\ \text { Reliability } \\ \text { Variance } \\ \text { Extracted }\end{array}\end{array}$

(AVE)

\begin{tabular}{lll}
\hline $\begin{array}{l}\text { Employees' } \\
\text { performance }\end{array}$ & 0.836 & 0.630 \\
$\begin{array}{l}\text { Finance Business } \\
\text { Partnering }\end{array}$ & 0.873 & 0.697 \\
$\begin{array}{l}\text { Firms' Financial } \\
\text { Performance }\end{array}$ & 0.889 & 0.800 \\
$\begin{array}{l}\text { Internal Process } \\
\text { performance }\end{array}$ & 0.864 & 0.679 \\
$\begin{array}{l}\text { Market } \\
\text { Performance }\end{array}$ & 0.917 & 0.734 \\
\hline
\end{tabular}

Source: PLS Output

Based on table 3 above, it can be seen the results of the average variance extracted (AVE) value and the composite reliability value. The recommended AVE value is a value greater than 0.5 , the AVE results from this study are known to be above 0.5 , which means the variance that can be explained by the indicator is above 50\%. Composite reliability aims to test the reliability or consistency of latent or construct variables, where the composite reliability value is above 0.7 , it can be said that the latent variable has good reliability. Based on table 3 above, it is known that all latent variables from the study have a composite reliability value above 0.7 .

\section{Result of The Model}

In this study the partial least square model concerning finance business partnering is as follows:

Table 4. Estimation Results of The Partial Least Square Finance Business Partnering Model

\begin{tabular}{|c|c|c|c|c|}
\hline & Coeff. & STDEV & $\begin{array}{c}\mathbf{T} \\
\text { Statistics }\end{array}$ & $\begin{array}{c}\mathbf{P} \\
\text { Values }\end{array}$ \\
\hline EP ->FFP & 0.385 & 0.094 & 4.114 & 0.000 \\
\hline FBP->EP & 0.507 & 0.069 & 7.384 & 0.000 \\
\hline FBP->FFP & 0.218 & 0.085 & 2.563 & 0.011 \\
\hline FBP->IPP & 0.257 & 0.097 & 2.636 & 0.009 \\
\hline FBP->MP & 0.194 & 0.103 & 1.882 & 0.060 \\
\hline IPP->FFP & 0.187 & 0.090 & 2.085 & 0.038 \\
\hline MP->FFP & -0.018 & 0.113 & 0.164 & 0.870 \\
\hline
\end{tabular}

Source: PLS Output

The causality result of this study can also be shown in the following image:

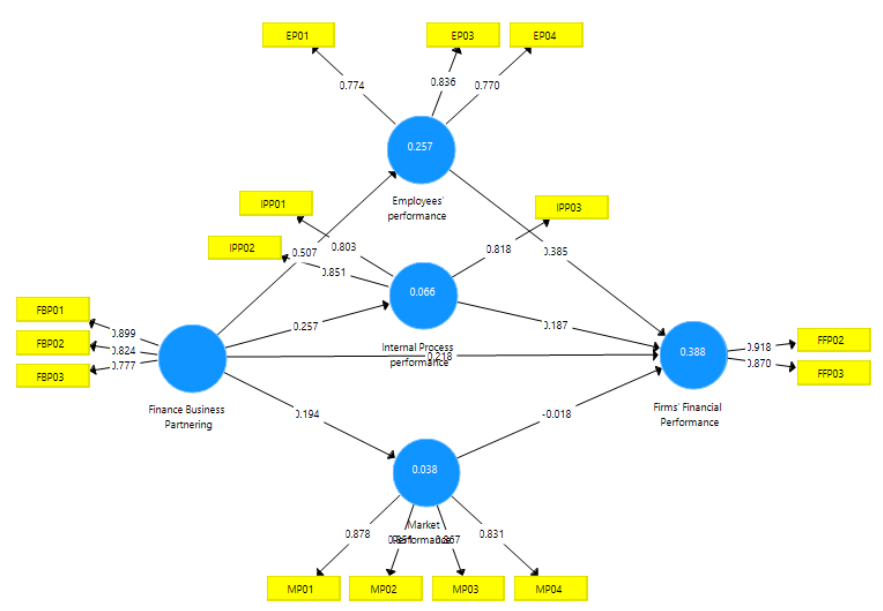

Fig 2. Model of Finance Business Partnering

The results estimation of the research model are as follows:

$F F P=0.218 F B P+0.385 E P+0.187 I P P-0.018 M P$

$E P=0.507 F B P$

$I P P=0.257 F B P$

$M P=0.194 F B P$

From the structural equation, it can be seen that: 
a. The latent variable of FBP has a positive and significant effect on the latent variable of FFP with a path coefficient of 0.218 and a p-value of 0.011 . This means that the greater the FBP, the higher the FFP.

b. The latent variable of EP has a positive and significant effect on the latent variable of FFP with a path coefficient of 0.385 and a $p$-value of 0.000 . This means that the greater the EP, the FFP will increase.

c. The latent variable of IPP has a positive and significant effect on the latent variable of FFP with a path coefficient of 0.187 and a p-value of 0.038 . This means that the greater the IPP, the higher the FFP

d. The latent variable of MP has a negative and insignificant effect on the latent variable FFP with a path coefficient of 0.018 and a $p$-value of 0.870 . This means that the greater the MP, the lower the FFP, but the decrease is not significant.

e. The latent variable of FBP has a positive and significant effect on the latent variables of $\mathrm{EP}$ with a path coefficient of 0.507 and $p$-value 0.009 . This means that the greater the FBP, the EP will increase.

f. The latent variable of FBP has a positive and significant effect on the latent variable of IPP with path coefficient 0.257 and p-value 0.009. This means that the greater the FBP, the IPP will increase.

g. The latent variable of FBP has a positive and insignificant effect on the MP latent variable with a path coefficient of 0.194 and a p-value of 0.060 . This means that the greater the FBP, the MP will increase, but the increase is not significant.

Tabel 5. Indirect Effect

\begin{tabular}{lcc}
\hline & $\begin{array}{l}\text { Original } \\
\text { Sample } \\
(\mathbf{O})\end{array}$ & P Values \\
\hline FBP $>$ FFP through & 0.195 & 0.003 \\
EP & & \\
FBP -> FFP through & 0.056 & 0.066 \\
IPP & & \\
FBP -> FFP through & -0044 & 0.870 \\
MP & \\
\hline
\end{tabular}

Source: PLS output and Sobel Test
1. The path coefficient of the indirect effect of FBP on FFP through EP is 0.195 with a p-value of 0.003 (significant at the 5\% level). The positive indirect path coefficient indicates that the greater the FBP, the greater the FFP mediated by EP

2. The path coefficient of the indirect effect of FBP on FFP through IPP is 0.056 with a p-value of 0.066 (not significant at the 5\% level, but significant at the $10 \%$ level). The positive indirect path coefficient indicates that the greater the FBP, the greater the FFP will be mediated by IPP

3. The path coefficient of the indirect effect of FBP on FFP through MP is -0.044 with a p-value of 0.870 (not significant at the $5 \%$ or $10 \%$ level). The negative indirect path coefficient indicates that the greater the FBP, the lower the FFP will be mediated by IPP, but the decrease is not significant.

As shown in Table 5, the indirect effect of FBP on firm's financial performance through employee performance is significant with a $\mathrm{p}$-value of 0.003 . Therefore, employee performance will play a fully mediating role in the relationship between FPB and the firms' financial performance. The employees' performance related to their knowledge, skills, education, and employee satisfaction can motivate in making process. So that, these factors will improve the firm's financial performance.

Concerning the internal process performance that is related to service, product or new product, and the speed of delivery [26]. The result clearly shows its role as mediating variable. Internal process performance (IPP) significantly mediates finance business partnering (FBP) to firm's financial performance (FFP).

In these cases, employee performance and internal process performance contribute to achieving the firm's financial performance.

However, the market performance (MP) does not mediate the relationship between finance business partnering (FBP) and firm's financial performance (FFP). The market performance is related to market share, new clients, and customer satisfaction. These factors do not contribute to the firm's financial performance significantly. 


\section{CONCLUSION}

Based on the results obtained, it can be concluded that partial least squares can be used to model finance business partnering. Modeling results show the financial business partnering significant effect on employees 'performance, firms' financial performance and internal process performance; employees 'performance has a significant effect on firms' financial performance; Internal process performance has a significant effect on firms' financial performance. Market performance is known to be a significant effect on firms' financial performance. The results also show that the financial business performance significantly influences on firms' financial performance through employees' performance.

This study has certain limitations. First, due to sampling limitations, the generalizability of the results is limited. The second limitation relates to the scale of the variables. Third, the respondents of this study were limited to manufacturing companies. Therefore, the validity of the results for other samples is limited and should be considered with caution. Fourth, this paper only considers finance staff as respondents, and the potential for bias may exist. Finally, this study uses cross-sectional data to examine the relationship between variables; the effect of lengthy finance business partnering

\section{REFERENCES}

[1] J. F. Hair, W. C. Black, B. J. Babin, and R. . Anderson, Multivariate Data Analysis. UK: Pearson Prentice Hall, 2010.

[2] J. Esteves, J. Casanovas, and J. Pastor, "Modeling With Partial Least Squares Critical Sucsess Factors Interrelationships In ERP Implementations," in the Ninth Americas Conference on Information Systems, 2003.

[3] O. B. Korkmazoglu and G. Kemalbay, "Econometrics Application of Partial Least Squares Regression: An Endogenous Growth Model for implementation on firm performance may have been negligible.

Due to the limitations of this study, we provide some suggestions for future research. First, this study used only 150 questionnaires, and collected 99 complete questionnaires to conduct data analysis, these findings may not be generalized to other manufacturing companies, so case studies or field studies are desirable to be conducted as a complement to the survey method. Second, this study is an exploratory study and some of the measures and scales applied were not tested empirically. Future studies are suggested to develop a series of actions from different perspectives, such as providing the necessary information, providing support, analysis and so on, enabling an accurate investigation of the implementation of FBP. Third, this study focuses on manufacturing companies only, therefore, future studies might consider selecting samples from nonmanufacturing industries, such as the financial and construction industries should be investigated by future research.

\section{ACKNOWLEDGMENT}

The authors are supported by the office of research of Universitas Nusantara PGRI Kediri, Faculty of Economics and Business, East Java, Indonesia. We also would like to thank LPPM UN PGRI Kediri for their contribution and participation in this study.

Turkey," Procedia - Soc. Behav. Sci., vol. 62, no. 1986, pp. 906-910, 2012.

[4] B. Morard and D. Simonin, "Partial Least Squares Modeling in Marketing Research: A Tailor-Made Model of Wine e-Commerce Consumers in Switzerland," J. Econ. Bus. Manag., vol. 4, no. 5, pp. 410-417, 2016.

[5] Y. Fan et al., "Applications of structural equation modeling (SEM) in ecological studies: an updated review," Ecol. Process., vol. 5, no. 1, 2016.

[6] J. Henseler, G. Hubona, and P. A. Ray, "Using PLS path modeling in new technology research: Updated 
guidelines," Ind. Manag. Data Syst., vol. 116, no. 1, pp. 2-20, 2016.

[7] A. Tohari, "Pemodelan Derajat Kesehatan Menggunakan Structural Equation," J Stat., vol. 10, no. 2, pp. 16, 2017.

[8] F. Faisol, "Islamic Bank Financing and It's Impact on Small Medium Enterprise's Performance," ETIKONOMI, 2017.

[9] A. Shuhaiber, The role of perceived control, enjoyment, cost, sustainability and trust on intention to use smart meters: An empirical study using SEM$P L S$, vol. 746. Springer International Publishing, 2018.

[10] U. Yudatama, A. N. Hidayanto, B. A. A. Nazief, and K. Phusavat, "Data to model the effect of awareness on the success of IT Governance implementation: A partial least squares structural equation modeling approach (PLS-SEM)," Data Br., vol. 25, p. 104333, 2019.

[11] J. Mohammad, F. Quoquab, F. Idris, M. Al Jabari, and R. Wishah, "The mediating role of overall fairness perception: a structural equation modelling assessment," Empl. Relations, vol. 41, no. 3, pp. 614-636, 2019.

[12] A. Manfrin, B. Apampa, and P. Parthasarathy, "A conceptual model for students' satisfaction with team-based learning using partial least squares structural equation modelling in a faculty of life sciences, in the United Kingdom," J. Educ. Eval. Health Prof., vol. 16, pp. 1-9, 2019.

[13] J. Benitez, J. Henseler, A. Castillo, and F. Schuberth, "How to perform and report an impactful analysis using partial least squares: Guidelines for confirmatory and explanatory IS research," Inf. Manag., vol. 57, no. 2, p. 103168, 2020.
[14] CGMA, "Finance Business Partnering: The Conversations that Count," p. 28, 2015.

[15] L. Zoni and K. A. Merchant, "Controller involvement in management: An empirical study in large Italian corporations," J. Account. Organ. Chang., vol. 3, no. 1, pp. 29-43, 2007.

[16] I. Ciftci, E. Tatoglu, G. Wood, M. Demirbag, and S. Zaim, "Corporate governance and firm performance in emerging markets: Evidence from Turkey," Int. Bus. Rev., vol. 28, no. 1, pp. 90-103, 2019.

[17] N. Hussain, U. Rigoni, and R. P. Orij, "Corporate Governance and Sustainability Performance: Analysis of Triple Bottom Line Performance," $J$. Bus. Ethics, vol. 149 , no. 2, pp. 411432, 2018.

[18] M. V. Achim, S. N. Borlea, and C. Mare, "Corporate Governance and Business Performance: Evidence for the Romanian Economy," J. Bus. Econ. Manag., vol. 17, no. 3, pp. 458-474, 2016.

[19] I. Hasan, N. Kobeissi, L. Liu, and H. Wang, "Corporate Social Responsibility and Firm Financial Performance: The Mediating Role of Productivity," J. Bus. Ethics, vol. 149, no. 3, pp. 671-688, 2018.

[20] W. Sun, C. Zhao, and C. H. Cho, "Institutional transitions and the role of financial performance in CSR reporting," Corp. Soc. Responsib. Environ. Manag., vol. 26, no. 2, pp. 367-376, 2019.

[21] R. J. Indjejikian, "indjijekan and Matejka 2006.pdf," vol. 81, no. 4, pp. 849-872, 2006.

[22] I. Ghozali and H. Latan, Partial Least Squares: Konsep, Teknik dan Aplikasi SmartPLS 2.0 M3. Semarang: Badan Penerbit Universitas Diponegoro, 2013.

[23] J. Henseler, C. M. Ringle, and R. R. Sinkovics, "The use of partial least squares path modeling in international 
52 Jurnal IImiah KURSOR Vol. 11, No. 1, Juli 2021, hal 43 - 52

marketing," Adv. Int. Mark., vol. 20, pp. 277-319, 2009.

[24] I. G. N. M. Jaya and I. M. Sumertajaya, "Pemodelan Persamaan Struktural Dengan Partial Least Square," in Paper presented at the Seminar Nasional Matematika dan Pendidikan Matematika, 2008.

[25] J. J. F. Hair, G. T. M. Hult, C. M. Ringle, and M. Sarstedt, A Primer on Partial Least Squares Structural
Equation Modeling. SAGE Publications, Inc., 2014.

[26] J. Kallunki, E. K. Laitinen, and H. Silvola, "International Journal of Accounting Information Systems Impact of enterprise resource planning systems on management control systems and firm performance," Int. J. Account. Inf. Syst., vol. 12, no. 1, pp. 20-39, 2011. 